\title{
Intensive-care management of snakebite victims in rural sub-Saharan Africa: An experience from Uganda
}

\author{
H J Lang, ${ }^{1}$ MD, FRCPCH; J Amito, ${ }^{1}$ BME (Anaesthesia); M W Dünser, ${ }^{2} \mathrm{MD}, \mathrm{PD} ; \mathbf{R}$ Giera, ${ }^{2} \mathrm{MD}$; R Towey, ${ }^{1} \mathrm{MB} \mathrm{ChB}$, FRCA \\ ${ }^{1}$ St. Mary's Hospital Lacor, Gulu, Uganda \\ ${ }^{2}$ Department of Anaesthesiology and Intensive Care Medicine, Kepler University Hospital and Johannes Kepler University, Linz, Austria
}

Corresponding author: H J Lang (Hajoe123@yahoo.es)

Background. Antivenom is rarely available for the management of snakebites in rural sub-Saharan Africa(sSA).

Objective. To report clinical management and outcomes of 174 snakebite victims treated with basic intensive-care interventions in a rural sSA hospital.

Methods. This cohort study was designed as a retrospective analysis of a database of patients admitted to the intensive care unit (ICU) of St. Mary's Hospital Lacor in Gulu, Uganda (January 2006 - November 2017). No exclusion criteria were applied.

Results. Of the 174 patients admitted to the ICU for snakebite envenomation, 60 (36.5\%) developed respiratory failure requiring mechanical ventilation (16.7\% mortality). Results suggest that neurotoxic envenomation was likely the most common cause of respiratory failure among patients requiring mechanical ventilation. Antivenom (at probably inadequate doses) was administered to 22 of the 174 patients (12.6\%). The median (and associated interquartile range) length of ICU stay was 3 (2 - 5) days, with an overall mortality rate of $8 \%$. Of the total number of patients, 67 (38.5\%) were younger than 18 years.

Conclusion. Results suggest that basic intensive care, including mechanical ventilation, is a feasible management option for snakebite victims presenting with respiratory failure in a rural sSA hospital, resulting in a low mortality rate, even without adequate antivenom being available. International strategies which include preventive measures as well as the strengthening of context-adapted treatment of critically ill patients at different levels of referral pathways, in order to reduce deaths and disability associated with snakebites in sSA are needed. Provision of efficient antivenoms should be integrated in clinical care of snakebite victims in peripheral healthcare facilities. Snakebite management protocols and preventive measures need to consider specific requirements of children.

Keywords. Africa, essential emergency and critical care, ICU management, mechanical ventilation, snakebite.

S Afr J Crit Care 2020;36(1):39-45. https://doi.org/10.7196/SAJCC.2020.v36i1.404

\section{Contribution of study}

It is estimated that up to 138000 people die each year following snakebites. Currently, reliable provision of efficient snake-bite antivenom is challenging in many rural health facilities in sub- Saharan Africa (sSA). Our results suggest that basic intensive-care interventions, including mechanical ventilation, is a feasible management option for critically ill snakebite victims in a rural sSA hospital, resulting in a low mortality rate, even without adequate antivenom doses being available.

Approximately 5.4 million people are bitten by snakes annually, with up to half of these victims experiencing signs of envenomation. This results in an estimated 138000 deaths per year. ${ }^{[1]}$ Only limited data exist on the long-term morbidity of snakebites, but one study suggested that between 5900 and 14600 amputations per year may be attributed to snakebites in sub-Saharan Africa (sSA) alone. ${ }^{[2]}$ However, accuracy of epidemiological data is limited owing to under-reporting, patients' poor access to healthcare facilities and many victims attending traditional healers rather than health centres or hospitals..$^{[1-3]}$

The burden of snakebites is unevenly distributed across the globe, with $95 \%$ of cases encountered in low- and middle-income countries in Africa and Asia. ${ }^{[4,5]}$ Even in those areas, the health effects of snakebites are disproportional, with the poorest of the poor generally experiencing poor outcomes. ${ }^{[6,7]}$ Rural sSA is specifically vulnerable owing to limited availability of healthcare services. In 2017, the World Health Organization (WHO) recognised snakebite envenoming as a neglected tropical disease. ${ }^{[7]}$ Accordingly, snakebite antivenoms are included in the WHO's list of essential medicines. ${ }^{[8]}$

Common acute medical conditions arising from snakebites depend on the species, but include neurotoxicity, coagulation failure accompanied by shock or organ dysfunction, and local tissue destruction. ${ }^{[9]}$ Multiple factors, including delayed presentation to healthcare facilities, adversely affect the management and outcome of snakebite victims. ${ }^{[2]}$ Inadequate regulatory frameworks that result in ineffective or unsafe antivenom products being available, restricted access and high costs are crucial challenges limiting the use of antivenoms, particularly in sSA. ${ }^{[10,11]}$ Supportive measures are often the only therapeutic options for patients presenting with snakebite envenoming in sSA.

In this study, we report the intensive care unit (ICU) management and outcomes of 174 snakebite victims who were treated mainly with basic intensive-care interventions (e.g. mechanical ventilation) in a rural sSA hospital where adequate doses of antivenom were not available. 


\section{Methods}

This cohort study was designed as a retrospective analysis of a prospectively collected database of patients admitted to the ICU of St. Mary's Hospital Lacor in Gulu, Uganda, between 1 January 2006 and 30 November 2017. All patients from this database admitted to the ICU because of snakebite envenomation were included in the analysis. No exclusion criteria were applied. The analysis of the ICU data was approved by the institutional review board of the hospital. Owing to the retrospective design of the study, written and oral consent was waived. Selected data of 139 patients were included in a previous analysis reporting on admission diagnoses, use of mechanical ventilation and outcomes of critically ill patients treated at this ICU. ${ }^{[12]}$

\section{Study setting}

St. Mary's Hospital Lacor is a private, non-profit (former mission) hospital located in the north of Uganda, serving 700 000 inhabitants in a poor, post-conflict area. It has 476 beds and six operating rooms, with $\sim 5000$ surgeries being performed per annum. Using subsidised external funding, the hospital's objective is to provide barrier-free access to healthcare, particularly to the poorest of the community. The hospital also runs an eight-bed ICU where critically ill patients are admitted. The unit has eight trained nurses and four assistant nurses (with one nurse attending to between four and eight patients per shift). The medical responsibility for an ICU patient is shared by one anaesthetic officer and a physician. This team was assisted by a senior anaesthetist from 2002 to 2016. Table 1 outlines the operational features of the unit, as described previously. ${ }^{[12]}$

\section{Patient management}

Patients with snakebite envenoming account for 2 - 3\% of the ICU population at this centre. ${ }^{[12]}$ General principles of critical care were applied to stabilise vital organ functions. Specific treatment of snakebites was provided with available resources according to WHO guidelines. ${ }^{[9]}$ All snakebite victims were continually monitored using non-invasive measurements (e.g. electrocardiogram, respiratory rate, peripheral oxygen saturation, non-invasive blood pressure and temperature). Respiratory support included the provision of supplemental oxygen and advanced airway management, as well as invasive mechanical ventilation for airway protection or in the case of respiratory failure. Mechanical ventilation was initiated when the attending anaesthetist judged patient survival to be at risk within an hour of assessment.

Adequate antivenom doses could not be provided in the majority of cases because of limited availability of appropriate antivenom. Safety and efficacy of the antivenom available at the ICU during the study period (VINS Bioproducts, India) has not yet been confirmed for use in Africa by the WHO validation processes. Experts from the WHO, the Global Snakebite Initiative and Médecins sans Frontières (MSF) recommend using products with better neutralisation capacity, such as the South African Institute for Medical Research (SAIMR) polyvalent antivenom; ${ }^{[9,13]}$ however, this is more expensive than the VINS antivenom. The MSF Operational Centre in Geneva recently recommended a new algorithm for the management of snakebite victims in South Sudan, namely the use of Echitab-Plus for cytotoxic and haemotoxic envenoming (vipers and spitting cobras) and the SAIMR polyvalent antivenom for neurotoxic envenoming (cobras and mambas). ${ }^{[13]}$

When antivenom was available for the treatment of critically ill snakebite victims described in this study, usually only one vial could be administered; in special cases, two vials could be administered if indicated. WHO and MSF guidelines indicate that in persisting snakebite syndromes, several vials of antivenom are needed to achieve adequate neutralisation of snake toxins and clinical stabilisation. ${ }^{[9,13]}$ In view of the limited availability of effective antivenom, advanced airway management and mechanical ventilation were prioritised over antivenom therapy in critically ill patients with signs of neurotoxic snakebite envenoming (e.g. fasciculation, paralysis and respiratory failure).

The snake could rarely be identified by patients or relatives. No DNA sequencing techniques from swabs of bite sites could be performed for identification purposes. ${ }^{[14]}$

\section{Data analysis}

The following data were collected from all patients included in this analysis: gender, age, therapeutic interventions (continuous monitoring; endotracheal intubation and mechanical ventilation; tracheostomy; antivenom therapy), complications, length of ICU stay, and mortality. Clinical symptoms of patients documented in the database were categorised as fasciculation/paralysis (due to neurotoxicity), coagulopathy/shock/haemolysis, or extensive tissue damage.

All statistical analyses were performed using the PASW statistical software package (version 20.0) (IBM Corp., Austria). We compared the occurrence of and variables related to different envenoming symptoms (fasciculation/paralysis, coagulopathy/shock/haemolysis or extensive tissue damage) between survivors and non-survivors using chi-squared, Mann-Whitney $U$-rank sum and Fisher's exact tests, as appropriate. Data are presented as absolute values with percentages in parentheses, or median values along with interquartile ranges (IQRs). A significance level $p<0.05$ was used.

\section{Results}

Of the 6976 patients admitted to the ICU during the study period, 174 were treated for snakebite envenomation (2.5\%). More than a third of the patients were younger than 18 years $(n=67 ; 38.5 \%)$ (Fig. 1). As shown in Table 2, non-survivors more frequently presented with coagulopathy, shock or haemolysis than survivors. Invasive mechanical ventilation was used more often for treating non-survivors than survivors. Complications were documented for more non-survivors than survivors. Antivenom (at low and probably inadequate doses ${ }^{[9,13]}$ ) was administered to $12.6 \%$ of patients $(n=22)$. The median (IQR) length of ICU stay was $3(2-5)$ days and overall mortality was recorded as $8 \%(n=14)$.

Information on clinical symptoms at presentation could be extracted from the database for 40 patients (23\%) (Table 3). The need for invasive mechanical ventilation and subsequent ICU mortality differed among snakebite victims who presented with clinical symptoms.

Table 4 summarises the characteristics of patients who required mechanical ventilation $(n=60 ; 34.5 \%)$. Among these, clinical symptoms were documented in more detail in only 16 cases. Neurotoxicity (fasciculation/paralysis) was the most commonly documented indication for advanced respiratory support (87.5\%). However, it should be noted that in the absence of any other documented complication, it can be assumed that patients with respiratory failure requiring mechanical ventilation experienced neurotoxic snakebite syndrome. Antivenom could be administered only to $10(16.7 \%)$ of the 60 patients who required mechanical ventilation; three of these patients died (33.3\%). Of the 50 ventilated patients who did not receive antivenom treatment, seven died (14\%). There was no statistical difference in mortality between mechanically ventilated patients with or without antivenom therapy ( $p=0.35$; Fisher's exact test). 
Table 1. Operational characteristics of the intensive care unit at St. Mary's Lacor Hospital, Uganda ${ }^{[12]}$

\begin{tabular}{|c|c|}
\hline Characteristic & Description \\
\hline Admission criteria & $\begin{array}{l}\text { Patients with life-threatening conditions requiring immediate intervention } \\
\text { Patients with abnormal vital signs or other clinical concerns requiring close observation and treatment } \\
\text { Postoperative care in case intensive care or close observation is required. } \\
\text { These criteria were also applied to snakebite victims. }\end{array}$ \\
\hline Beds & 8 permanent beds; additional beds can be added if needed. \\
\hline Nurse:patient ratio & 1 nurse for every $4-8$ patients \\
\hline Doctors/clinical officers & $\begin{array}{l}\text { One anaesthetic officer and the admitting physician share the medical responsibility for the ICU patients. } \\
\text { A senior anaesthetist dedicated full clinical responsibility to the ICU (full-time consultant from } 2002 \text { to 2008; part-time } \\
\text { consultant from } 2009 \text { to 2016). }\end{array}$ \\
\hline Monitoring & $\begin{array}{l}\text { Pulse oximeters: } 2 \\
\text { Non-invasive blood pressure machines: } 3 \\
\text { Multiparameter monitors: } 1 \\
\text { 12-lead electrocardiograph: } 1 \\
\text { Capnography: not available (end-tidal } \mathrm{CO}_{2} \text { monitoring should be considered as an essential element during intubation and } \\
\text { surveillance of mechanically-ventilated patients) }\end{array}$ \\
\hline Equipment - examples & $\begin{array}{l}\text { Basic resuscitation equipment } \\
\text { Equipment for advanced airway management } \\
\text { Ventilators capable of providing intermittent positive pressure ventilation (Glostavent; Diamedica, UK): } 3 \\
\text { Oxygen concentrators (10 1/min): } 3 \\
\text { Oxygen cylinders: limited supply } \\
\text { Equipment for chest drain insertion } \\
\text { Single-lumen central lines (as well as peripheral venous and intraosseous access) }\end{array}$ \\
\hline Management options & $\begin{array}{l}\text { Routine resuscitation measures } \\
\text { Respiratory care } \\
\text { Basic and advanced airway management } \\
\text { Insertion of chest drains (e.g. for management of empyema, pneumothoraces) and aspiration of pleural effusions } \\
\text { Low-flow } \mathrm{O}_{2} \text { and } \mathrm{O}_{2} \text { supplementation via face mask } \\
\text { Advanced airway management and mechanical ventilation; non-invasive respiratory support was not available during } \\
\text { the study period. } \\
\text { Circulation } \\
\text { Fluid management and blood transfusions } \\
\text { Peripheral and central line insertion; no arterial lines used. } \\
\text { Occasional adrenaline or dopamine infusions }\end{array}$ \\
\hline \multirow[t]{3}{*}{$\begin{array}{l}\text { Management of } \\
\text { neurological emergencies }\end{array}$} & $\begin{array}{l}\text { Management of comatose patients and status epilepticus } \\
\text { No intracranial pressure monitoring } \\
\text { Medication }\end{array}$ \\
\hline & $\begin{array}{l}\text { Enteral and intravenous medications (based on national guidelines and the WHO list of essential medications }{ }^{[8]} \text { ) } \\
\text { Essential antibiotics, including ceftriaxone, ciprofloxacin (no carbapenems, amikacin or vancomycin) } \\
\text { Nutrition }\end{array}$ \\
\hline & $\begin{array}{l}\text { Enteral nutritional support; parenteral nutrition not routinely used. } \\
\text { Renal replacement therapy } \\
\text { Peritoneal dialysis could be performed by the end of the study period, on rare occasions; not used in the patients } \\
\text { described in this study. }\end{array}$ \\
\hline Laboratory & $\begin{array}{l}\text { Point-of-care tests: malaria rapid diagnostic tests (available later during the study period); blood glucose, urine analysis } \\
\text { Blood films (e.g. for detection of malaria parasites), haemoglobin and full blood count } \\
\text { Analysis of CSF } \\
\text { Rapid tests: HIV, hepatitis B and C, syphilis } \\
\text { Sputum: tuberculosis smears (no Gen-Xpert was available during the study period) } \\
\text { Not routinely available: electrolyte analysis, blood gas analysis, renal or liver function tests, clotting tests, no blood or CSF } \\
\text { cultures. }\end{array}$ \\
\hline Blood bank & $\begin{array}{l}\text { Blood bank: rapid and safe blood transfusion services } \\
\text { Not available: Tranexamic acid, fresh-frozen plasma, platelet concentrates }\end{array}$ \\
\hline Imaging & $\begin{array}{l}\text { Portable X-ray } \\
\text { Ultrasound by a radiologist (no routine availability of point-of-care ultrasound) }\end{array}$ \\
\hline Protocols & $\begin{array}{l}\text { General principles of anaesthetics and critical care were followed. } \\
\text { WHO management guidelines were followed for children. } \\
\text { WHO protocols for snakebites }{ }^{[9]} \text { were followed with available resources (e.g. antivenom was administered only in a minority } \\
\text { of patients). }\end{array}$ \\
\hline Training & $\begin{array}{l}\text { The clinical staff consist of nurses, anaesthetic officers who receive regular on-the-job training and coaching by an } \\
\text { experienced senior anaesthesist, and visiting critical care doctors. The hospital invested in the training of nurses and } \\
\text { anaesthetic clinical officers for several years. These training programmes are recognised by the Ugandan Minstry of Health. }\end{array}$ \\
\hline $\begin{array}{l}\text { Logistics, pharmacy and } \\
\text { biomedical support }\end{array}$ & $\begin{array}{l}\text { The hospital has a strong logistics and pharmacy team. Cleaners and ICU staff ensure infection prevention and control measures. } \\
\text { Reliable maintenance and repair services are provided by a skilled and supportive biomedical department. }\end{array}$ \\
\hline Electricity & The hospital has a reliable electricity system. \\
\hline
\end{tabular}


Table 2. Characteristics of the study population $(N=174)$

\begin{tabular}{|c|c|c|c|c|}
\hline Characteristic & All $(N=174), n(\%)^{*}$ & Survivors $(N=160), n(\%)^{\star}$ & Non-survivors $(N=14), n(\%)^{*}$ & $p$-value ${ }^{\dagger}$ \\
\hline \multicolumn{5}{|l|}{ Demographics } \\
\hline Male & $90(51.7)$ & $82(51.3)$ & $8(57.1)$ & 0.78 \\
\hline Age (years), median (IQR) & $24(12-34)$ & $24(12-35)$ & $19(8-29)$ & 0.92 \\
\hline$<5$ & $12(6.9)$ & $9(5.6)$ & $3(21.4)$ & 0.06 \\
\hline $5-10$ & 25 (14.4) & $24(15)$ & $1(7.1)$ & 0.7 \\
\hline $11-18$ & $30(17.2)$ & $27(16.9)$ & $3(21.4)$ & 0.71 \\
\hline$>18$ & $107(61.5)$ & $100(62.5)$ & $7(50)$ & 0.4 \\
\hline \multicolumn{5}{|l|}{ Clinical presentation $(N=40)$} \\
\hline Fasciculation/paralysis, $n / N(\%)$ & $23 / 40(57.5)$ & $19 / 32(59.4)$ & $4 / 8(50)$ & 0.7 \\
\hline Coagulopathy/shock/haemolysis, $n / N(\%)$ & $5 / 40(12.5)$ & $2 / 32(6.3)$ & $3 / 8(37.5)$ & $0.046^{\ddagger}$ \\
\hline Extensive tissue damage, $n / N(\%)$ & $12 / 40(30)$ & $11 / 32(34.4)$ & $1 / 8(12.5)$ & 0.4 \\
\hline \multicolumn{5}{|l|}{ ICU care } \\
\hline Invasive mechanical ventilation & $60(34.5)$ & $50(31.3)$ & $10(71.4)$ & 0.006 \\
\hline Tracheostomy & $1(0.6)$ & 0 & $1(7.1)$ & 0.08 \\
\hline Antivenom therapy & $22(12.6)$ & $18(11.3)$ & $4(28.6)$ & 0.08 \\
\hline \multicolumn{5}{|l|}{ Outcome } \\
\hline Any complication ${ }^{\ddagger}$ & $6(3.4)$ & $3(1.9)$ & $3(21.4)$ & 0.007 \\
\hline Length of ICU stay (days), median (IQR) & $3(2-5)$ & $3(2-5)$ & $3(2-5)$ & 0.99 \\
\hline \multicolumn{5}{|l|}{ ICU mortality } \\
\hline$<18$ years, $n / N(\%)$ & 7/67 (10.4) & $\mathrm{n} / \mathrm{a}$ & $\mathrm{n} / \mathrm{a}$ & $\mathrm{n} / \mathrm{a}$ \\
\hline$>18$ years $n / N(\%)$ & $7 / 105(6.5)$ & $\mathrm{n} / \mathrm{a}$ & $\mathrm{n} / \mathrm{a}$ & $\mathrm{n} / \mathrm{a}$ \\
\hline
\end{tabular}

The ICU mortality of patients requiring mechanical ventilation was $16.7 \%$. Of the 60 patients who required mechanical ventilation, $17(28.3 \%)$ were younger than 18 years; six with respiratory failure died (35.3\% mortality). Among these 17 patients were two children younger than 5 years, both of whom died. Of the 43 patients older than 18 years who required mechanical ventilation, four died (9.3\% mortality). The difference in mortality rates between children and adults requiring mechanical ventilation was statistically significant ( $p=0.02$; Fisher's exact test).

Length of ICU stay (Fig. 2A) and mortality (Fig. 2B) were significantly higher in patients requiring mechanical ventilation than in those who did not need advanced respiratory support.

\section{Discussion}

This analysis reports the ICU management and outcomes of 174 snakebite victims, of whom approximately a third were younger than 18 years, in a rural hospital in northern Uganda. The study setting appears comparable to other rural healthcare regions in SSA, which are characterised by single hospitals that serve large catchment areas and support a number of peripheral healthcare facilities. In contrast with many other facilities in $\mathrm{SSA},{ }^{[15,16]}$ our centre runs an ICU that can provide basic intensive-care interventions, including

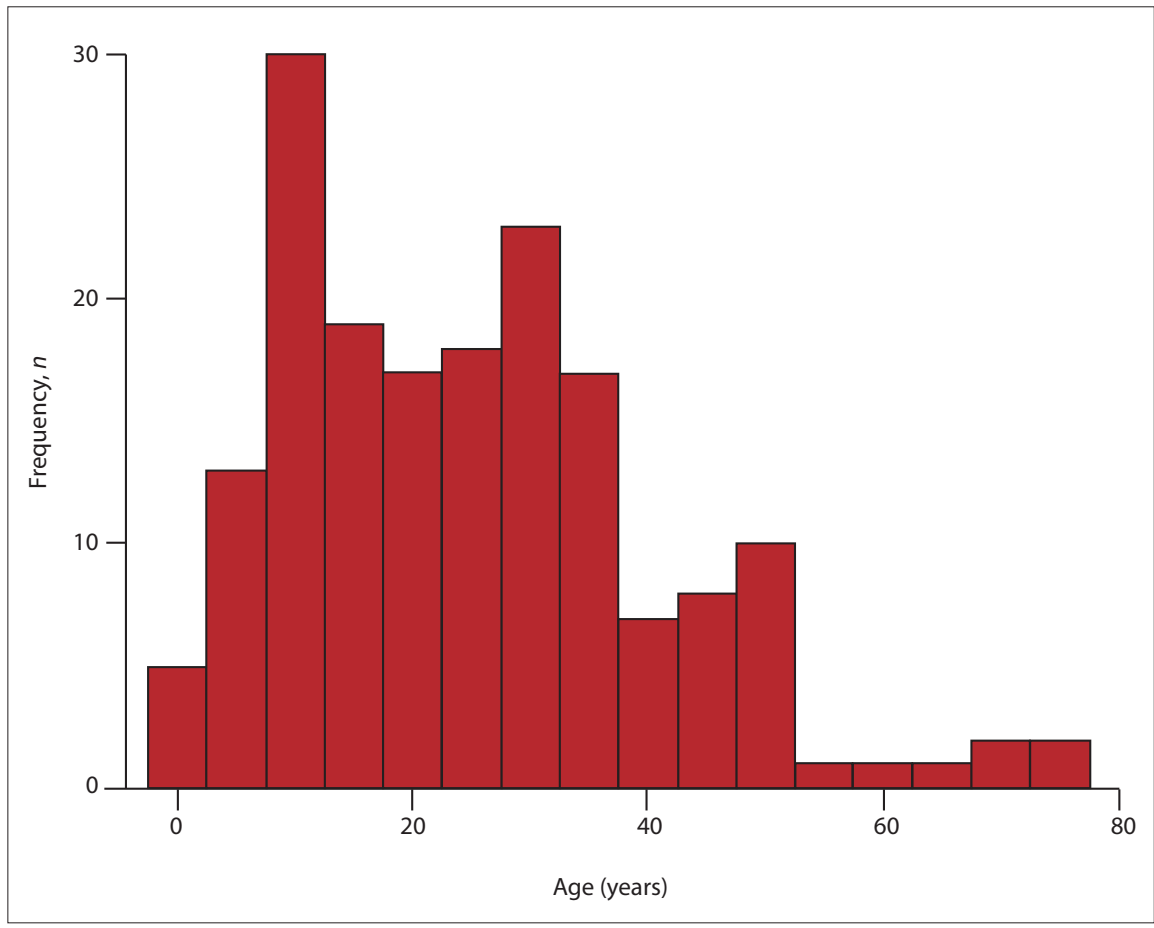

Fig. 1. Age distribution of snakebite victims treated at the intensive care unit at St. Mary's Lacor Hospital, Uganda $(\mathrm{N}=174)$.

mechanical ventilation. ${ }^{[12]}$ To put this into perspective, a recent survey revealed that one ICU bed is available per 1000000 inhabitants in Uganda. ${ }^{[17]}$

Snakebite envenoming accounted for $2.5 \%$ of all ICU admissions at our centre. Clinical symptoms, which could retrospectively be determined for approximately a quarter of the study population, suggest that neurotoxic symptoms were encountered most frequently. We observed an overall mortality rate of $8 \%$.

The cohort of 174 patients described in this study reflects the most severe cases of hospitalised snakebite victims. Unfortunately, 


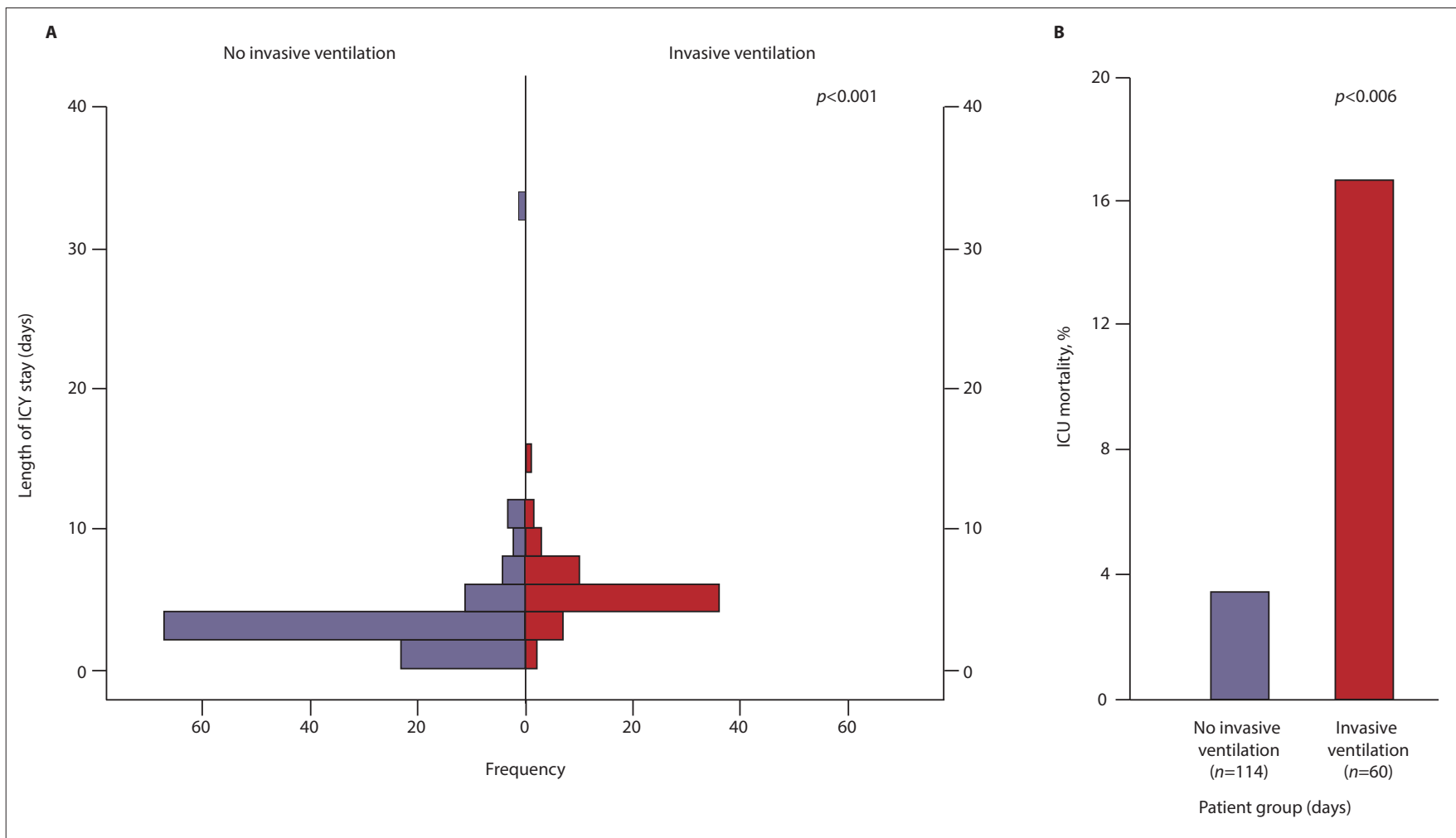

Fig. 2. (A) Length of stay in the intensive care unit for patients requiring invasive ventilation $(\mathrm{n}=60)$ compared with patients not requiring invasive ventilation ( $\mathrm{n}=114)$. (B) Mortality of snakebite victims for patients requiring invasive ventilation $(\mathrm{n}=60)$ compared with patients without severe respiratory failure $(\mathrm{n}=114)$.

Table 3. Characteristics of patients according to clinical presentation $(N=40)$

\begin{tabular}{|c|c|c|c|c|}
\hline Characteristic & $\begin{array}{l}\text { Fasciculation/paralysis } \\
(N=23), n(\%)^{\star}\end{array}$ & $\begin{array}{l}\text { Coagulopathy/shock/ } \\
\text { haemolysis }(N=5), n(\%)^{*}\end{array}$ & $\begin{array}{l}\text { Extensive tissue damage } \\
(N=12), n(\%)^{*}\end{array}$ & $p$-value \\
\hline \multicolumn{5}{|l|}{ Demographics } \\
\hline Male & $14(60.9)$ & $2(40.0)$ & $7(58.3)$ & 0.7 \\
\hline Age (years), median (IQR) & $28(12-34)$ & $9(5-30)$ & $11(4-35)$ & 0.07 \\
\hline \multicolumn{5}{|l|}{ ICU care } \\
\hline Monitoring & $23(100)$ & $5(100)$ & $12(100)$ & 1 \\
\hline Mechanical ventilation & $14(60.9)$ & $1(20)$ & $1(8.3)$ & $0.007^{\dagger}$ \\
\hline Tracheostomy & 0 & 0 & 0 & 1 \\
\hline Antivenom therapy & $4(17.4)$ & $2(40.0)$ & $3(25.0)$ & 0.53 \\
\hline \multicolumn{5}{|l|}{ Outcome } \\
\hline Any complication ${ }^{*}$ & $3(13.0)$ & $1(20.0)$ & 0 & 0.35 \\
\hline Length of ICU stay (days), median (IQR) & $4(2-6)$ & $8(6-11)$ & $4(3-6)$ & 0.16 \\
\hline ICU mortality & $4(17.4)$ & $3(60.0)$ & $1(8.3)$ & $0.047^{\dagger}$ \\
\hline ICU mortality of ventilated patients, $n / N(\%)$ & $4 / 14(28.6)$ & $1 / 1(100)$ & $1 / 1(100)$ & 0.15 \\
\hline
\end{tabular}

the hospital information system does not provide data on the number of patients referred from peripheral facilities or hospitalised snakebite patients who did not need ICU admission during the study period. Although reliable regional epidemiological data regarding snakebites are scarce, ${ }^{[2,5]}$ Uganda is considered to have a relatively high incidence of snakebite envenomation and faces considerable challenges in providing adequate access to basic emergency care for snakebites, especially in rural areas. ${ }^{[5]}$

All patients included in the study received continuous monitoring in the ICU. Approximately a third of the patients required advanced interventions, such as invasive mechanical ventilation. As this was a nonrandomised cohort study, it is not possible to determine the true treatment effect of mechanical ventilation on mortality in our study population. However, the higher mortality rate and longer ICU stays reported for patients who required invasive mechanical ventilation compared with those who did not need ventilatory support likely reflect the high disease severity and risk of death in patients in whom mechanical ventilation was instituted. The authors are not aware of existing systematic data in peer- reviewed literature describing the clinical outcomes of neurotoxic snakebite victims with respiratory failure, treated in healthcare facilities without the facilities providing mechanical ventilation.

The risk of mortality among patients who develop paralysis and acute respiratory insufficiency following a snakebite is likely to be very high without mechanical ventilation. ${ }^{[18-21]}$ As the fatality rate among snakebite 
Table 4. Characteristics of snakebite victims requiring invasive mechanical ventilation $(N=60)^{*}$

\begin{tabular}{ll}
\hline Characteristic & $n(\%)$ \\
\hline Demographics & $40(66.7)$ \\
Male & $28(16-35)$ \\
Age (years), median (IQR) & \\
Clinical presentation $(N=16)$ & $14(87.5)$ \\
Fasciculation/paralysis & $1(6.3)$ \\
Coagulopathy/shock/haemolysis & $1(6.3)$ \\
Extensive tissue damage & \\
ICU carew & $60(100)$ \\
$\begin{array}{l}\text { Monitoring } \\
\text { Tracheostomy }\end{array}$ & $1(1.7)$ \\
$\begin{array}{l}\text { Antivenom therapy } \\
\text { Outcome }\end{array}$ & $10(16.7)$ \\
Any complication & \\
Length of ICU stay & $5(8.3)$ \\
ICU mortality & $5(4-6)$ \\
IQR = interquartile range; ICU = intensive care unit. \\
${ }^{*}$ Further clinical symptoms were documented in 16 cases. \\
${ }^{\dagger}$ Complications included acute lung injury $(n=1)$, acute renal failure $(n=1)$, bed sore \\
$\begin{array}{l}n=1) \text {, ascites }(n=1) \text { and aspiration pneumonia }(n=1) . \\
\end{array}$
\end{tabular}

victims who received mechanical ventilation in our cohort was low (16.7\%), mechanical ventilation can be considered to have been a lifesaving intervention for the majority of patients with acute respiratory failure, particularly those presenting with neurotoxic symptoms.

Slightly more than one-third of patients in this cohort were younger than 18 years, with $7 \%$ younger than 5 years (Fig. 1, Table 2). In $2017,48 \%$ of the Ugandan population was younger than 14 years; ${ }^{[22]}$ this age group is slightly under-represented in our cohort. Children older than 5 years may be exposed to a higher risk of snakebite than younger children owing to the activities they are involved in (e.g. exposure during play, on their way to school, assisting the family with agricultural work). Adolescents and adults involved in manual labour (e.g. in the agricultural sector) seem to carry the highest risk for exposure to venemous snakes. ${ }^{[1,9]}$

Fatality rates associated with snakebite in children are generally higher than in adults, possibly due to the smaller volume of distribution and consequently higher toxin levels in children. ${ }^{[9,23,24]}$ Although insignificant $(p=0.4)$ in the analysis of the cohort of all 174 patients, mortality in children was higher compared with adult patients $(10.4 \%$ v. $6.5 \%)$. In the analysis of 60 patients with respiratory failure requiring mechanical ventilation, mortality among children $>18$ years $(N=17)$ was significantly higher than among adult patients $(35.3 \%$ v. $9.3 \%$; $p=$ 0.02). These findings highlight that interventions to prevent snakebites as well as management strategies for snakebite victims need to address particular needs of children and adolescents. ${ }^{[25]}$

Most of the snakebite victims in our cohort did not receive what would be regarded as adequate antivenom doses by international standards, ${ }^{[9,13]}$ owing to difficulties in the supply chain, poor local economic conditions and limited donor capacity. This finding reflects and highlights the challenges of provision and use of antivenom in rural sSA. ${ }^{[10,11,26]}$ Considering findings from Sri Lanka, which showed that snakebite victims presenting with signs of severe neurotoxicity progressed to respiratory failure requiring mechanical ventilation even when antivenom had been given, ${ }^{[27]}$ it is unlikely that antivenom alone is sufficient to treat critically ill snakebite patients. A study from India reported no fatalities in 51 patients with neurotoxic snake envenomation after they were treated with a combination of antivenom therapy and mechanical ventilation. ${ }^{[28]}$ In our study only a small number of patients
(16.7\%) with respiratory failure and who required mechanical ventilation received antivenom. The antivenom used during the study period is not among the products currently recommended by international specialists in this field. ${ }^{[9,13]}$ It could therefore not be determined whether early administration of adequate doses of appropriate antivenom combined with advanced airway management and mechanical ventilation could have improved survival rates or reduced the required duration of mechanical ventilation.

In this study, acetyl-cholinesterase inhibitors (ACHEIs) were not routinely used in the management of patients with neurotoxic snakebite syndromes. Evidence regarding the role of ACHEIs (e.g. neostigmine) in the management of muscle paralysis following neurotoxic snakebite is limited. ${ }^{[21]} \mathrm{A}$ beneficial role of ACHEIs is not confirmed by WHO guidelines for envenomation from possible mamba bites. ${ }^{[9]}$ Mamba bites are common causes of severe neurotoxic envenomation in eastern and southern Africa. ${ }^{[9]}$

\section{Study limitations}

Important limitations need to be considered when interpreting the data of our study. First, our analysis was designed retrospectively, which explains why the presenting clinical symptoms of snakebite victims could be determined in only $23 \%$ of the patients included in the analysis. Our findings therefore offer insight merely into the differences in management and outcome of patients presenting with different snakebite-associated clinical syndromes. Second, the nonrandomised study design precludes conclusions on the true outcome effects of intensive-care interventions, including mechanical ventilation, in critically ill snakebite patients.

\section{Conclusion}

Despite the limitations of this study, our results suggest that provision of basic intensive care, including mechanical ventilation, was a feasible treatment option for critically ill snakebite victims presenting with respiratory failure in a rural sSA hospital when adequate antivenom doses were unavailable. An international strategy focused on preventive measures and community engagement to reduce deaths and disability associated with snakebites in SSA is required. Strengthening of contextadapted treatment of critically ill patients, including snakebite victims, at various levels of the referral pathway is important. The provision and administration of efficient and safe antivenoms should be integrated in the clinical care of snakebite victims in rural and peripheral healthcare facilities. Snakebite management protocols and preventive measures need to consider specific requirements of children. Pragmatic operational research can contribute to advance strategies aimed at integrating prevention of snakebites and improving clinical care of snakebite victims.

\section{Declaration. None.}

Acknowledgements. Our sincere thanks and admiration to all workers of the ICU at the St. Mary's Lacor Hospital, and in particular to the dedicated nurses, for their excellent patient care and record-keeping. We also acknowledge the valuable advice and support from Gabriel Alcoba (Tropical Medicine Advisor, MSF Operational Centre - Geneva).

Author contributions. HJL was responsible for review of the ICU's database and identification of the specific outcomes of patients presenting with snakebite envenomation, and contributed substantially to the review of data analysis and manuscript development. MWD led the data analysis process, supported by RG and JA. RT was responsible for setting up the ICU's data- 
base and contributed to data collection for the study, supported by JA. All co-authors (JA, MWD, RG and RT) supported HJL in writing and reviewing of the manuscript.

Funding. None.

Conflicts of interest. None.

1. World Health Organization. Snakebite envenoming. https://www.who.int/news-room/fact-sheets detail/snakebite-envenoming (accessed 23 June 2020).

2. Chippaux JP. Estimate of the burden of snakebites in sub-Saharan Africa: A meta-analytic approach. Toxicon 2011;57(4):586-599. https://doi.org/10.1016/j.toxicon.2010.12.022

3. Sloan DJ, Dedicoat MJ, Lalloo DG. Healthcare-seeking behaviour and use of traditional healers after snakebite in Hlabisa sub-district, KwaZulu-Natal. Trop Med Int Health 2007;12(11):1386-1390. https://doi.org/10.1111/j.1365-3156.2007.01924.x

4. Kasturiratne A, Wickremasinghe AR, De Silva N, et al. The global burden of snakebite: A literature analysis and modelling based on regional estimates of envenoming and deaths. PLoS Med 2008;5(11):e218. https://doi.org/10.1371/journal.pmed.0050218

5. Longbottom J, Shearer FM, Devine M, et al. Vulnerability to snakebite envenoming: A global mappin of hotspots. Lancet 2018;392(10148):673-684. https://doi.org/10.1016/S0140-6736(18)31224-8

6. Harrison RA, Hargreaves A, Wagstaff SC, Faragher B, Lalloo DG. Snake envenoming: A disease of poverty. PLoS Negl Trop Dis 2009;3(12):e569. https://doi.org/10.1371/journal.pntd.0000569

7. Chippaux JP. Snakebite envenomation turns again into a neglected tropical disease! J Venom Anim Toxins Incl Trop Dis 2017;23:38. https://doi.org/10.1186\%2Fs40409-017-0127-6

8. World Health Organization. WHO Model List of Essential Medicines. 21st list. Geneva: WHO, 2019 https://www.who.int/medicines/publications/essentialmedicines/en/

9. World Health Organization. Guidelines for the Prevention and Clinical Management of Snakebite in Africa. Geneva: WHO, 2010. https://www.who.int/snakebites/resources/9789290231684/en/

10. Brown NI. Consequences of neglect: Analysis of the sub-Saharan African snake antivenom market and the global context. PLoS Negl Trop Dis 2012;6(6):el670. https://doi.org/10.1371/journal. pntd.0001670

11. Habib AG, Brown NI. The snakebite problem and antivenom crisis from a health-economic perspective. Toxicon 2018;150:115-123. https://doi.org/10.1016/j.toxicon.2018.05.009

12. Dunser MW, Towey RM, Amito J, Mer M. Intensive care medicine in rural sub-Saharan Africa Anaesthesia 2017;72(2):181-189. https://doi.org/10.1111/anae.13710

13. Alcoba G, Mwongera C, Baba SP, et al. Use of two antivenoms for snakebite envenoming in Agok, South Sudan. Trans R Soc Trop Med Hyg 2019;113(Suppl 1):Abstract 166.

14. Sharma SK, Kuch U, Höde P, et al. Use of molecular diagnostic tools for the identification of species responsible for snakebite in Nepal: A pilot study. PLoS Negl Trop Dis 2016;10(4):e0004620. https:// doi.org/10.1371/journal.pntd.0004620
15. Baker T. Critical care in low-income countries. Trop Med Int Health 2009;14:143-148. https://doi. org/10.1111/j.1365-3156.2008.02202.x

16. Baelani I, Jochberger $\mathrm{S}$, Laimer $\mathrm{T}$, et al. Identifying resource needs for sepsis care and guideline implementation in the Democratic Republic of the Congo: A cluster survey of 66 hospitals in four eastern provinces. Middle East J Anaesthesiol 2012;21(4):559-575.

17. Kwizera A, Dünser M, Nakibuuka J. National intensive care unit bed capacity and ICU patient characteristics in a low income country. BMC Res Notes 2012;5:475. https://doi org/10.1186/1756-0500-5-475

18. Alirol E, Sharma SK, Bawaskar HS, Kuch U, Chappuis F. Snake bite in South Asia: A review. PLoS Negl Trop Dis 2010;4(1):e603. https://doi.org/10.1371/journal.pntd.0000603

19. Fox S, Rathuwithana AC, Kasturiratne A, Lalloo DG, De Silva HJ. Underestimation of snakebite mortality by hospital statistics in the Monaragala District of Sri Lanka. Trans R Soc Trop Med Hyg 2006;100(7):693-695. https://doi.org/10.1016/j.trstmh.2005.09.003

20. Sharma SK, Chappuis F, Jha N, Bovier PA, Loutan L, Koirala S. Impact of snake bites and determinants of fatal outcomes in southeastern Nepal. Am J Trop Med Hyg 2004;71(2):234-238. https://doi.org/10.4269/ajtmh.2004.71.234

21. Ranawaka UK, Lalloo DG, De Silva HJ. Neurotoxicity in snakebite - the limits of our knowledge. PLoS Negl Trop Dis 2013;7(10):e2302. https://doi.org/10.1371/journal.pntd.0002302

22. United Nations Population Fund. Population Matters - Uganda Population Dynamics. 2017 Kampala: UNPF, 2017. https://uganda.unfpa.org/sites/default/files/pub-pdf/Issue $\% 20$ Brief\%20 1\%20-\%20Population\%20dynamics.\%20Final.\%2010.5.2017.pdf.

23. Sankar J, Nabeel R, Sankar MJ, Priyambada L, Mahadevan S. Factors affecting outcome in children with snake envenomation: A prospective observational study. Arch Dis Child 2013;98(8):596-601. https://doi.org/10.1136/archdischild-2012-303025

24. Dandona R, Kumar GA, Kharyal A, George S, Akbar M, Dandona L. Mortality due to snakebite and other venomous animals in the Indian state of Bihar: Findings from a representative mortality study. PLoS One 2018;13(6):e0198900. https://doi.org/10.1371/journal.pone.0198900

25. World Health Organization. Snakebite Envenoming. A Strategy for Prevention and Control. Geneva: WHO, 2019. https://www.who.int/snakebites/resources/9789241515641/en/

26. Williams DJ, Faiz MA, Abela-Ridder B, et al. Strategy for a globally coordinated response to a priority neglected tropical disease: Snakebite envenoming. PLoS Negl Trop Dis 2019;13(2):e0007059. https://doi.org/10.1371/journal.pntd.0007059

27. Silva A, Maduwage K, Sedgwick M, et al. Neuromuscular effects of common krait (Bungarus caeruleus) envenoming in Sri Lanka. PLoS Negl Trop Dis 2016;10(2):e0004368. https://doi org/10.1371/journal.pntd.0004368

28. Sarin K, Dutta TK, Vinod KV. Clinical profile \& complications of neurotoxic snake bite \& comparison of two regimens of polyvalent anti-snake venom in its treatment. Indian J Med Res 2017;145(1):58-62. https://doi.org/10.4103/ijmr.ijmr_1319_14

Accepted 22 January 2020 